\title{
Homenagem ao centenário Celso Furtado, esse paraibano genial
}

O Programa de Pós-Graduação em Ciências Jurídicas (PPGCJ) do Centro de Ciências Jurídicas da Universidade Federal da Paraíba (UFPB) foi criado em 1996, com o mestrado em Direito Econômico. Em 2004, foi agregada a segunda área de concentração, através do mestrado em Direitos Humanos, e pouco tempo depois, em 2010, foi aprovado o curso de doutorado em Direitos Humanos $e$ Desenvolvimento. Nessa trajetória de ampliação e consolidação podem ser encontrados importantes marcos de fundamentação teórica, que foram dando sustentação e coerência à sua estrutura interdisciplinar.

Alguns doutrinadores merecem ser recordados e reafirmados, do início até agora, sempre em diálogo com as novas tendências. De cabeça, posso referenciar e reverenciar nomes como Eros Roberto Grau e o seu A Ordem Econômica na Constituição de 1988; o eterno Washington Peluso Albino de Souza e os seus Teoria da Constituição Econômica e Primeiras Linhas de Direito Econômico, que forneciam à Academia brasileira muito mais do que uma leitura introdutória da temática; os portugueses Vital Martins Moreira, jurisconsulto e político, meu orientador no doutorado em Coimbra, Joaquim José Gomes Canotilho, grande teórico das Constituições luso-brasileiras, e 
o querido amigo e proeminente nome da economia política internacional, António José Avelãs Nunes; o francês Gerard Farjat, personagem importante do Droit Économique; os caríssimos jusfilósofos italianos Norberto Bobbio, Mario Losano e Danilo Zolo, estes últimos docentes visitantes do PPGCJ (por longo tempo) e mentores respeitados nas temáticas dos impactos da globalização econômica sobre a democracia e o Estado de Direito; os ilustres nomes da USP ligados ao Direito Internacional, como Luiz Olavo Baptista, João Grandino Rodas e José Roberto Franco da Fonseca, para citar os mais próximos ao PPGCJ.

Nos eixos Meio Ambiente, Justiça Social e Desenvolvimento, e suas transversalidades, o PPGCJ adotou a fundamentação teórica de autores como Paulo Afonso Leme Machado, José Afonso da Silva, Enrique Leff, Fábio Comparato, Boaventura Santos, Gilberto Bercovici, Calixto Salomão Filho e Luiz Carlos Bresser-Pereira. No conjunto do quadro conceitual aqui sumariado, e que naturalmente não terá sido esgotado, pedindo perdão por omissões imperdoáveis, esta autora confere especial destaque a dois nomes: Amartya Sen e Celso Furtado, com suas visões múltiplas de justiça redistributiva e desenvolvimento, acerca da essência da dimensão humana dessa vertente conceitual, sendo possível caminhar pelo colóquio entre suas teorias.

As luzes trazidas por estes pensadores para a construção do argumento científico da pós-graduação stricto sensu de uma Instituição pública de ensino, localizada em região pobre do Brasil, comprometida com o estudo da realidade regional, como a UFPB, levaram à identificação de suas proposições como marcos teóricos precursores e fundantes. Isso sem mencionar o desmedido respeito que os paraibanos têm por esse conterrâneo excepcional, Celso Furtado, nascido na cidade de Pombal (1920-2004). No cotejo entre ambos, mencione-se de início a ênfase especial atribuída por Sen para o incremento das liberdades substantivas e das capacidades humanas, como fim primordial e meio principal para se alcançar o desenvolvimento com justiça, enquanto que, em Furtado, o 
desenvolvimento representa a dimensão política das decisões econômicas ou o processo que vislumbra o aumento de produtividade para resgate do social e para a realização das potencialidades humanas, com promoção da capacidade criativa das pessoas para o incremento de técnicas produtivas e concomitante formulação de valores existenciais, rumo ao seu bem-estar, em movimento conduzido pelo Estado.

Entre ambos os autores, as conexões são evidentes e abordadas pelo próprio Celso, para quem Amartya é "um imaginativo inovador na problemática complexa da interdisciplinaridade no campo das ciências sociais". Foram contemporâneos na Universidade de Cambridge, descendentes do ramo keynesiano, tendo frequentado juntos os seminários de Nicholas Kaldor - ao recordar-se disso, Celso Furtado quase lamenta não ter-se aproximado mais de Amartya Sen naquela época, declarando que pensara se tratar de "mais um desses talentos de país subdesenvolvido destinado a ser cooptado pelo rico mundo universitário dos EUA".

Anos mais tarde, no exílio, depois da experiência exitosa da Sudene (Superintendência de Desenvolvimento do Nordeste), como política de desenvolvimento regional que repercutiu mundialmente, inclusive na Índia, os dois voltaram a se encontrar. A convite de Amartya Sen, que promoveu importante encontro entre economistas interessados em problemas de desenvolvimento na sua própria casa, Furtado passou a avultar, com respeito, os ensaios de Amartya Sen sobre Desigualdade Econômica, de 1973, e sobre Poverty and Famines, de 1981, nos quais o indiano, prêmio Nobel de Economia, de 1998, introduziu o conceito de entitlement ("habilitação"), tratando como poucos a situação da fome epidêmica e da pobreza endêmica no mundo, que jamais, segundo ele, seria resolvida pelo simples aumento da oferta de bens essenciais nos países afetados, posto que, para participar da distribuição da renda, seria "necessário estar habilitado 
por título de propriedade ou por inserção qualificada no sistema produtivo".

Para ele, assim como para Furtado, existem problemas estruturais impossíveis de ser enfrentados por soluções advindas dos mecanismos de mercado. Reconheciam, ambos, no mundo periférico, a presença de sociedades nas quais as pessoas simplesmente não estão licenciadas para participar do processo de desenvolvimento econômico, como é o caso da falta de títulos para acessar terras (pelas populações rurais) ou acessar moradia (pelas populações urbanas). Isso se chama exclusão social. Há muita similaridade entre as proposições teóricas dos autores neste particular, com a distinção de que Sen, diferentemente de Furtado, não propunha ação mais abrangente do Estado, mas maior abrangência e atuação no plano da sociedade. Peço licença para concordar com Celso Furtado.

Feito o registro sobre esse duplo marco conceitual, assim como da interlocução identificada entre eles, cabe-me agora tentar significar a presença transversal do pensamento de Celso Furtado no PPGCJ da Universidade Federal da Paraíba. Em 2010, quando da apresentação da proposta de curso novo de doutorado à Capes, o Programa de PósGraduação encontrou no complexo tema do desenvolvimento (e seus desdobramentos) o vínculo teórico para equivaler os mestrados em Direito Econômico e Direitos Humanos, desse modo, a disciplina do desenvolvimento, proposta pela primeira vez em Paris, para estudantes da América Latina, na Sorbonne e no Institutut d'Études du Dévelopment Économique et Social, pelo próprio Celso Furtado, foi abraçada pela pós-graduação em Direito da UFPB. Quem, senão Celso Furtado, poderia oferecer material bibliográfico basal mais pertinente?

No entanto, na conjugação temática do desenvolvimento como direito humano não seria possível acolher proposições meramente economicistas, que usassem como referência de identificação somente o aumento do PIB, a acumulação de capital ou a renda real per capita. Aspectos mais relevantes do desenvolvimento econômico, sobretudo nas sociedades capitalistas, estão nas análises da desigualdade, do 
subdesenvolvimento e da pobreza, sendo necessário trazer pois ao debate aportes da sociologia, antropologia, história, política, cultura e direitos humanos. Desenvolvimento é processo, que recusa a linearidade da análise microeconômica do equilíbrio espontâneo de forças no mercado, posto depender de políticas de indução, com determinantes encontrados em fatores ideológicos, religiosos, culturais, políticos, entre outros.

Mesmo reconhecendo uma demarcação geral no entendimento de que a concepção de crescimento econômico importa para a configuração do desenvolvimento, o pensamento crítico a ser edificado no PPGCJ precisaria conjugar a análise econômica com o contexto social, em diálogo interdisciplinar, apto a valorizar igualmente aspectos políticos e institucionais. A conexão entre as relações sociais de produção, o estágio das forças produtivas e as formas de poder político (sobretudo na vertente político-jurídica), impacta o argumento jusconstitucionalista e a promoção internacional dos direitos humanos, formando um caldo doutrinário apropriado para analisar e definir processos históricos, gerando aportes científicos relevantes para o estudo de problemas locais e regionais.

Para aliar desenvolvimento econômico e direitos humanos é preciso construir séria inflexão sobre os caminhos e descaminhos do desenvolvimento; seus mitos e verdades; sua natureza e usos hegemônicos e contrahegemônicos; a compreensão do seu inverso (ou o subdesenvolvimento); as relações de dependência na periferia do sistema mundo; os falsos consensos impostos pelas "metrópoles imperiais"; os jogos estratégicos do poder. Esta breve descrição, por si, mostra a complexidade da conjugação das temáticas e das teorias que encerra, considerado que desenvolvimento, assim como direitos humanos, são expressões fluidas, voláteis, criticadas, que somente podem ser explicadas e compreendidas diante do processo histórico, da luta, da tomada de posição dos agentes.

Celso Furtado, ao estudar as "raízes do subdesenvolvimento", denunciou os conglomerados empresarias como fenômenos decorrentes do que chamou de "capitalismo pós-cíclico”, em remissão 
às sucessivas etapas de prosperidade e depressão características do sistema. Para abrigar-se dos riscos, historicamente, o capitalismo se subdividiu em diversos setores produtivos, atuando em muitos mercados e armado de grande poder financeiro, para despontar no fenômeno do consumismo e do descarte de produtos, com excepcional capacidade de manobra da sociedade consumidora, do mercado e dos Estados. Este fato, na América Latina, teria forçado a renúncia da criação e consolidação de um sistema de produção articulado aos interesses da coletividade nacional, papel estratégico do Estado como instrumento estabilizador e regulador das economias nacionais, através principalmente das políticas monetária e fiscal.

No entanto, nessa etapa do capitalismo, cuja menção histórica circunda o final do século XX e começo do século XXI, guiado pelos interesses dos EUA (e não mais da Inglaterra), o poder de disposição dos Estados nacionais entrou em confronto com a natureza transfronteiriça das empresas (e dos conglomerados internacionais) como real centro de decisões, potencializado pelo avanço da eletrônica e do progresso tecnológico. Esse jogo irá se refletir nas políticas de emprego e trabalho, preços, urbanística, agrária e ambiental, entre outras, significando que, mais uma vez, salta aos olhos as conexões desta estrutura de pensamento com os temas tratados pelo Direito Econômico, nas interfaces com os direitos sociais e culturais, no PPGCJ.

Furtado expressa com clareza o papel do Estado na condução de um tipo de desenvolvimento plural, que se manifesta nas dimensões econômica e cultural, em contexto indissociável, para além das métricas quantitativas. Em Furtado, "as relações entre as variáveis econômicas são estabelecidas a partir de dados não-econômicos”, não representando mera questão de aumento de oferta de bens ou de acumulação de capitais. Repita-se, desenvolvimento é processo, ao mesmo tempo, de condução externa e de autotransformação social, capaz de satisfazer o horizonte de aspirações da coletividade, considerada não de maneira abstrata, mas pela concretude da identificação do seu perfil, assim, este modo de enxergar o 
desenvolvimento resta cuidadosamente significativo para a sua construção como direito humano de terceira geração, garantido mediante a Resolução $n^{0}$ 41/128 da Assembleia Geral das Nações Unidas, de 4 de dezembro de 1986.

O padrão teórico de similaridade e assimilação de conteúdo até aqui apresentado parece suficiente para evidenciar a aproximação entre o pensamento Celso Furtado e o PPGCJ. Tanto assim que este reconhecimento foi feito quando da realização do XXIII Congresso do Conselho Nacional de Pesquisa e Pós-Graduação em Direito (CONPEDI), dedicado ao tema A Humanização do Direito e a Horizontalização da Justiça no século XXI, ocorrido em João Pessoa, na UFPB, no período de 05 a 08 de novembro de 2014, que homenageou Celso Furtado, tendo sido entregue a premiação à esposa de Celso, jornalista e escritora Rosa Freire de Aguiar.

O pensamento de Celso Furtado é como uma fênix, com incrível capacidade de ressurgimento e reconhecimento a cada nova onda do capitalismo cíclico. Não posso terminar esta homenagem sem mencionar a atualidade de seus escritos no Brasil pandêmico (menção à COVID 19, mas não só) governado por Jair Bolsonaro. O fato é que, a partir do governo Temer e no atual governo, sob o argumento de que as políticas sociais extrapolam o orçamento da União, o cronograma político nacional foi marcado por reformas legislativas que afetaram a feição desenvolvimentista da carta constitucional e do Estado brasileiro, tendo sido aprovadas Leis e Emendas Constitucionais que lastrearam juridicamente o novo direcionamento da política econômica.

Citemos quatro casos. Ainda em 2016, foi aprovada a Emenda Constitucional 95, conhecida como Emenda do Teto dos Gastos Públicos, que alterou a Constituição brasileira para instituir novo regime fiscal, congelando o investimento público em saúde, educação e segurança nos patamares daquele ano para os próximos vinte anos; em seguida veio a reforma trabalhista, aprovada em 2017, que decompôs a Consolidação das Leis do Trabalho (CLT), fragilizando severamente a proteção dos trabalhadores e precarizando as relações 
de trabalho; a promulgação da Lei 13.874, de setembro de 2019, chamada Lei da Liberdade Econômica, que instituiu a Declaração de Direitos de Liberdade Econômica, estabelecendo garantias de livre mercado; e a entrada em vigor, em novembro de 2019, da chamada Nova Previdência, proposta pelo atual Ministro da Economia, Paulo Guedes, através da Emenda Constitucional no ${ }^{0} 103$, que modificou as regras para os segurados, com grande prejuízo social e humano.

Com a pandemia causada pelo coronavírus, essa cultura fiscal de austeridade, embora tendo esmorecido, não foi retirada de pauta. No Congresso estão a reforma tributária e a Proposta de Emenda Constitucional $\mathrm{N}^{\circ}$ 186, encaminhada em 2019, no objetivo de instituir controle ainda mais rigoroso sobre o chamado gasto público, que, na verdade, se trata de investimento público. Há um pacote, intitulado Plano Mais Brasil, que inclui esta e outras duas PECs - do Pacto Federativo e dos Fundos Públicos - para instituir mecanismos de coibição do endividamento público com despesas correntes, como salários do funcionalismo público, benefícios de aposentadoria, contas de energia e outros custeios. ${ }^{2}$

Esse conjunto de mudanças provoca o desmoronamento dos direitos sociais assim como afeta gravemente da pauta desenvolvimentista no país. O propósito é desconstruir ou destruir o Estado de Bem-Estar definido pela Constituição de 1988, assim como sua capacidade de financiamento do desenvolvimento, seja na vertente econômica, seja na vertente do direito humano ao desenvolvimento. Este não é o caminho proposto por Celso Furtado. A pandemia, a contrario sensu, mostrou que sua compreensão sobre o investimento público estava correta, não sendo este o maior problema brasileiro, mas sua principal solução, assim, a reviravolta pandêmica derrubou mitos sobre a questão fiscal, atingidos pela

\footnotetext{
2 Disponível em:

https://economia.uol.com.br/noticias/redacao/2019/11/05/bolsonaro-congressoreformas-economicas.htm?cmpid=copiaecola. Acesso em: $18 \mathrm{de} \mathrm{jul./2020}$ 
necessidade imediata de investimento em saúde, assistência social, pesquisas, apoio para as empresas e proteção aos trabalhadores.

Eis a pauta que se encontra na ordem do dia. O PPGCJ deve mergulhar nesses estudos para encontrar respostas científicas relevantes para o país, mostrando outros modos de encarar a realidade brasileira sem destruir a agenda desenvolvimentista, sem aniquilar conquistas históricas e sem abolir direitos. Incontinenti, registro, por oportuno, a imensa honra que representou para mim receber o convite do editor do Periódico científico Prima Facie, professor doutor Jailton Macena de Araújo, para produzir esta análise, em grata e sincera homenagem ao ilustre e respeitado conterrâneo Celso Furtado, no ano de centenário de seu nascimento.

João Pessoa, 26 de julho de 2020

\section{Maria Luiza Pereira de Alencar Mayer Feitosa}

Professora titular, docente permanente do PPGCJ e atual PróReitora de Pós-Graduação da UFPB

\section{REFERÊNCIAS}

FEITOSA, Maria Luiza Pereira de Alencar Mayer. Direitos Humanos de Solidariedade. Avanços e impasses. Curitiba: Appris.

FURTADO, Celso. A Economia Latino-Americana. São Paulo: Companhia das Letras.

FURTADO, Celso. Desenvolvimento e Subdesenvolvimento. Rio de Janeiro: Fundo de Cultura.

FURTADO, Celso. Diários Intermitentes. 1937-2002. São Paulo: Companhia das Letras.

FURTADO, Celso. Formação Econômica do Brasil. São Paulo: Companhia das Letras.

FURTADO, Celso. O Mito do Desenvolvimento Econômico. Rio de Janeiro: Paz e Terra.

FURTADO, Celso. Raízes do Subdesenvolvimento. Rio de Janeiro: Civilização Brasileira. 
FURTADO, Celso. Teoria e Política do Desenvolvimento Econômico. São Paulo: Paz e Terra, 10 ${ }^{\mathrm{a}}$. ed. revista pelo autor, 2000.

SEN, Amartya. Inequality reexamined. Nova York, Russel Sage Foundation.

SEN, Amartya. On economic inequality. Oxford: Clarendon Press.

SEN, Amartya. Poverty and Famines: an essay on entitlement and deprivation. Oxford: OUP Oxford. 